\title{
Los cultivos de cebolla y ajo en Colombia: estado del arte y perspectivas
}

\author{
Onion and garlic crops in Colombia: \\ current state and prospects
}

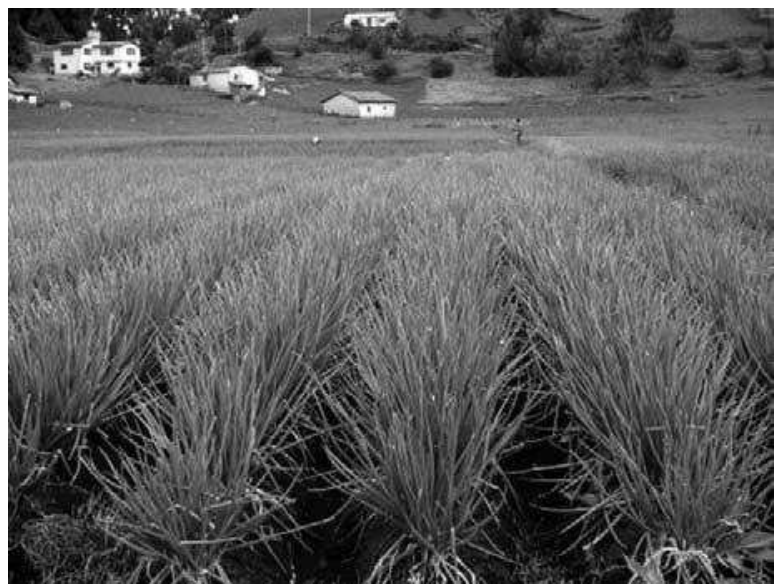

HERNÁN PINZÓN R. ${ }^{1}$

Cultivo de cebolla de rama en Aquitania, Boyacá.

Foto: H. Pinzón R.

\section{RESUMEN}

Los alliums comestibles que se cultivan en Colombia comprenden varias especies, pero sin duda las de mayor importancia económica son las cebollas de bulbo (incluyendo la ocañera), de rama y el ajo. Sus cultivos tradicionalmente se han localizado en valles de climas medios y fríos moderados de las regiones andinas y cercanos a los centros de consumo. El consumo de estas hortalizas se ha incrementado por sus cualidades condimentarias, asociada a sus beneficios de carácter medicinal. Su importancia socioeconómica es grande por la cantidad de mano de obra, directa e indirecta, asociada a los cultivos y por el capital invertido. Importantes problemas, especialmente de índole fitopatológica (hongos, bacterias y nemátodos en todas estas especies) y de semillas (en ajo, cebolla de rama y ocañera) han causado incremento de los costos de producción, baja en los rendimientos y por tanto disminución del área sembrada y desplazamiento de cultivos a otras zonas buscando suelos no infectados. En el ajo, lo anterior ha causado prácticamente su desaparición como cultivo y en la actualidad se importa casi el $90 \%$ de lo que se consume. El ICA y luego otras entidades de investigación y docencia, públicas y privadas, se han vinculado en la búsqueda de la solución a la problemática enunciada mediante proyectos de investigación. Los resultados hasta el momento son de carácter preliminar y desconocidos por la gran mayoría de productores. Falta una coordinación para integrar esfuerzos, los cuales han nacido y se han desarrollado aisladamente.

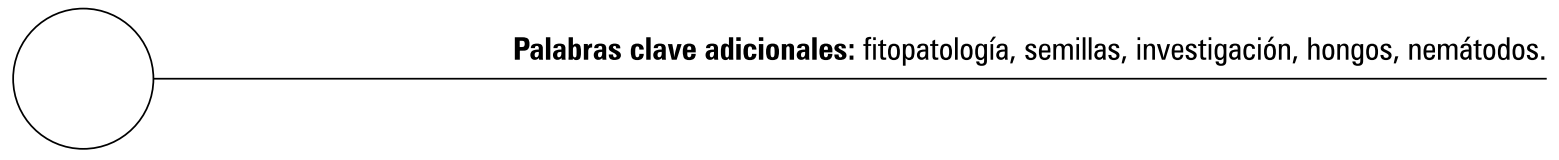

Asesor externo hortícola, Bogotá (Colombia). hpinzonra@yahoo.com 


\section{ABSTRACT}

The edible Allium plants grown in Colombia include several species, but without doubt the highest economic importance have bulb onions (including ocañera) and bunching onions and garlic. Their crops have traditionally been located in moderate and cold climate valleys of the Andean regions and close to centers of consumption. The consumption of these vegetables has increased by their condimentary qualities associated with the benefits of medicinal characteristics. Its economic importance is high due to the large amount of labor directly associated with cultivation and the capital invested. Major problems, especially phytopathological (fungi, bacteria and nematodes in all these species) and that of seeds (garlic, green onions and ocañera) have caused increased costs of production, low yields and, therefore, decrease the planted area of crops and cause movement to other areas seeking no infection lands. In garlic, these have caused virtually disappearance of it as a crop and now it is imported at almost $90 \%$ of what is consumed. ICA and then other research and teaching institutions, public and private, have been linked with the search to solve the problems listed by research projects. The results so far are preliminary and unknown by the vast majority of producers. There is a lack of coordination efforts to integrate these that have been born and developed in isolation.

Additional key words: plant pathology, seeds, research, fungi, nematodes.

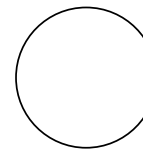

El botánico Hanelt (1990) dividió el género Allium en cinco subgéneros, dos de los cuales contienen las plantas comercialmente importantes (Brewster, 1990). La tabla 1 resume este esquema taxonómico y nos sirve para señalar las especies cultivadas en Colombia.
En Colombia, las más cultivadas y consumidas por su aroma, sabor y propiedades medicinales, a las cuales nos vamos a referir, son, en orden de importancia, la cebolla de bulbo, la cebolla de rama y el ajo.

Tabla 1. Grupos del género Allium en los que se incluyen los cultivos más importantes.

\begin{tabular}{|c|c|c|c|}
\hline Subgénero & Sección & Especies & Nombres vulgares \\
\hline \multirow{4}{*}{ Rhizirideum } & Rhizirideum & A. tuberosum & Cebollino chino \\
\hline & Schoenoprasum & A. schoenoprasum & Cebollín \\
\hline & \multirow{2}{*}{ Сepa } & A. сера & Cebolla de bulbo \\
\hline & & A. fistulosum & Cebolla de rama \\
\hline \multirow{3}{*}{ Allium } & \multirow{3}{*}{ Allium } & A. chinense & Rakkyo \\
\hline & & A. sativum & Ajo \\
\hline & & A. ampeloprasum & Puerro \\
\hline
\end{tabular}

Fuente: Hanelt, 1990. 
Los tipos de Allium cepa cultivados en Colombia se distribuyen en dos grupos hortícolas: el grupo de la cebolla común y el grupo de los agregados (Hanelt, 1990; Jones y Mann, 1963; Brewster, 1991). Al primer grupo corresponden las cebollas que más se consumen y son aquellas producto de semillas sexuales, importadas en su totalidad, y en el segundo grupo están las cebollas llamadas "ocañeras", producto de asexuales (bulbos).

La denominada cebolla de rama (A. fistulosum), conocida mundialmente como cebolla japonesa, se cultiva para obtener pseudotallos largos y blancos. El ajo tradicional de nuestro país corresponde a los llamados "ajos rosados" (Pinzón, 1999).

\section{DESCRIPCIÓN}

La cebolla de bulbo común tradicionalmente ha correspondido al tipo Yellow Granex, con bulbos grandes, aplanados y con piel de un color amarillo muy agradable; presenta problemas en almacenamiento debido a que su piel es muy fina (Acosta et al., 1993; Galmarini, 1990). En los últimos años, las evaluaciones de materiales (semillas) importados apuntan a seleccionar uno o varios híbridos tipo Sweet (menos picantes) y con ventajas para almacenar por un periodo mayor a dos meses (Pinzón, 1996). El sistema de producción de estas cebollas se realiza a partir de un semillero y su cultivo se realiza en muchos climas, especialmente en el frío, 2.600 msnm (Instituto Colombiano Agropecuario, 1983; Cásseres, 1980). Para 2007, el Ministerio de Agricultura y Desarrollo Rural reporta 11.500 ha cosechadas, una producción de 233.286 t y un rendimiento promedio de 19,7 t ha $\mathrm{a}^{-1}$. Los departamentos más productores son Boyacá (6.149 ha) y Cundinamarca (3.100 ha) (Agronet, 2009).

El otro tipo de cebolla de bulbo que se produce en Colombia corresponde a la llamada "ocañera", que se caracteriza porque su sistema de propagación se hace vegetativamente a partir de bulbos, luego la planta genera de 1 a 10 bulbos, pero prevalecen plantas de tres a siete bulbos de color rojo pálido a rosado claro y con fuerte sabor picante, apetecido especialmente en la Costa Atlántica (Vergel et al., 2003; Vergel et al., 2004). $\mathrm{Su}$ cultivo, localizado en zonas entre 1.200 y $1.900 \mathrm{msnm}$, prevalece en la Provincia de Ocaña (Norte de Santander) y para 2007 se cosecharon 4.300 ha, con una producción de 79.387 t.

La cebolla de rama es apetecida por su pseudotallo largo, jugoso y picante. Su sistema de producción se caracteriza por el abundante aporque (colocación de tierra a la base de la planta), lo cual favorece un abundante macollamiento (número de pseudotallos). Normalmente, a este cultivo se le pueden hacer varios cortes o cosechas (a partir de una sola siembra), el primer corte se hace entre los cinco y los seis meses y los posteriores cada dos a tres meses. Los rendimientos mínimos por corte están cerca de las $30 \mathrm{t} \mathrm{ha} \mathrm{a}^{-1}$, con un máximo de 75 t y un promedio de 40 t (Pinzón, 2004). Según el Ministerio de Agricultura y Desarrollo Rural, durante 2007 se cosecharon 6.900 ha y una producción de 184.000 t, la región con mayor área sembrada es Aquitania (Boyacá) con 2.425 ha. Este cultivo se adapta a casi todos los climas: la región de Aquitania es considerada zona de páramo (entre 3.000 y $3.400 \mathrm{msnm}$ ) y las demás regiones productoras están situadas en altitudes más bajas, con rangos entre 2.700 y 1.500 msnm (Raymond, 1990).

En Colombia, todos los materiales cultivados de ajo pertenecen al grupo de los rosados, y su cultivo se ha desarrollado en las subregiones del Altiplano Cundiboyacense, Altiplano de Nariño y Montaña Santandereana. En 2007, según el Ministerio de Agricultura y Desarrollo Rural, se sembraron 375 ha con una producción de 4.300 t y un rendimiento de 11,5 $\mathrm{t} \mathrm{ha}^{-1}$, las zonas más productoras son Santander (234 ha), Cundinamarca (70 ha) y Boyacá (35 ha). A pesar de la disminución del área sembrada, su consumo en el país ha tenido un notable incremento: de $0,29 \mathrm{~kg} /$ persona-año en 1992 a 0,50 kg/persona-año en 2001, frente a un consumo mundial de $0,80 \mathrm{~kg} /$ persona-año. 
Su participación en el gasto mensual de los colombianos es alto y por encima de muchas hortalizas consideradas de importancia. La baja en el área cultivada a nivel nacional ha causado un estímulo a las importaciones y más del 90\% del ajo que se consume proviene de China (Pinzón, 2008; Calderón, 1999; Departamento Administrativo Nacional de Estadística, 2001).

\section{PROBLEMÁTICA}

Los factores tecnológicos de la producción de estas especies en Colombia tienen características muy similares en las diferentes zonas de producción: baja sostenibilidad y competitividad, relacionadas principalmente con una compleja problemática sanitaria y de deterioro de los recursos ambientales, que resultan en bajos rendimientos y obligan al uso intensivo de agroquímicos (Pinzón, 1996). Esta situación ha desplazado el cultivo a muchas zonas (caso de Boyacá), elevando exageradamente los costos de producción, agudizando los procesos de deterioro ambiental y acentuando los riesgos para la salud humana. En ajo, esta situación produjo una reducción dramática del área sembrada (hasta 400 hectáreas en la actualidad), y como consecuencia las importaciones (principalmente de China) del ajo que se consume aumentaron hasta un $90 \%$.

Una descripción puntual de estos problemas es la siguiente:

Materiales de propagación: con excepción de la cebolla de bulbo común, los Alliums nombrados anteriormente son propagados vegetativamente. En Colombia no existen empresas o entidades creadas para la producción de esta clase de semillas y no existe una normatización por parte del Estado, por ello su mercado es caótico, teniendo como consecuencia un insumo de muy baja calidad sanitaria y agronómica (Pinzón, 2002, 2003). Los bulbos, pseudotallos y dientes, al no ser producidos adecuada y técnicamente, pueden ser portadores sistemáticos de nemáto- dos y algunas estructuras de reproducción de hongos, por tanto, al utilizarlos como semillas causan un efecto multiplicador de infección e infestación en los terrenos (López y Ávila, 1996; Rico y Ávila, 1989; Gaviola y Oliva, 1985; López y Heredia, 1997)

Enfermedades: son varios los patógenos que están afectando negativamente a los cultivos de cebollas y ajo, pero sin duda los que están causando mayor impacto socio-económico son los que afectan al sistema radicular y bulbos.

El nemátodo Ditylenchus dipsaci ha tomado mucha importancia en nuestro medio debido a su gran poder de diseminación a través de los dientes, gajos o bulbos utilizados como semillas y a su poder de infectar la planta a partir del suelo contaminado. Los adelantos en investigación demuestran la asociación de nemátodos con bacterias y nemátodos con hongos (Hio, 2009; Tovar et al., 1997). El hongo Sclerotium cepivorum, que causa la enfermedad llamada "pudrición blanca", es otro de los patógenos que está causando grandes pérdidas económicas, especialmente a los cultivos de cebolla común y ajo. En nuestro medio se constató una disminución en los rendimientos de los cultivos de ajo entre un $45 \%$ y $61 \%$, por ataque de virus igualmente se determinó una reducción del $17 \%$ en altura de las plantas y un 39\% en el peso de los dientes (Pinzón, 2008; Angarita, 1998; Ávila, 1996).

Estos dos problemas: semillas de mala calidad sanitaria y enfermedades han conformado un círculo vicioso e infeccioso que ha provocado desplazamientos de cultivos buscando zonas "nuevas" y, por tanto, han ampliado el radio de infección. En la mayor zona de producción de cebolla de rama, causó un descenso del número de "cortes" o cosechas de 18 a 3, a partir de una sola siembra (Herrera et al., 2006a) y, como se comentó antes, provocó un descenso vertiginoso del área nacional sembrada de ajo, trayendo como consecuencia el incremento en las importaciones. 
Poscosecha: la comercialización de nuestras cebollas y ajos en su gran mayoría se realiza sin o con un mínimo valor agregado. En el caso de las cebollas comunes, al momento de la cosecha sólo se eliminan pseudotallos y raíces y los bulbos no se curan, ni se someten a procesos de selección y clasificación. Es de anotar que la producción de esta cebolla es típicamente estacional, lo cual genera variaciones en los precios, restándole competitividad al cultivo, por lo cual es importante generar tecnología para su almacenamiento (Báez y Díaz, 2005; Herrera et al., 2006a). La cebolla de rama cosechada sólo tiene un proceso de presentación y transporte en las llamadas "ruedas". Por su parte, el ajo cosechado todavía conserva la tradicional y antitécnica presentación en "manojos" y tampoco se le hace selección ni clasificación.

Otros problemas: aparte de los problemas de tipo tecnológico que se presentan a nivel de cultivo, se encuentran otros de igual o mayor importancia, entre los cuales se destaca la deficiente comercialización. Colombia cuenta con centrales mayoristas de mercadeo creadas para, supuestamente, servir de apoyo al agricultor en la comercialización de sus productos, sin embargo, estos centros han caído en manos de unos pocos comercializadores que pagan valores arbitrarios por las cosechas, disminuyendo sensiblemente los ingresos de los productores (Alonso y Pinzón, 2002).

\section{RESPUESTAS DESDE LA INVESTIGACIÓN}

La investigación en los Alliums ha sido paralela al desarrollo de la investigación hortícola en Colombia: ésta se inició en 1959 en la División de Investigación Agropecuaria (DIA) y continuó con la creación del Instituto Colombiano Agropecuario (ICA) en 1963. En ese Instituto se creó el Programa de Investigación en Hortalizas y Frutales y en 1977 se estructuraron como programas independientes. En 1979, el ICA elaboró un diagnóstico del sector agropecuario, en el cual presentó la problemática tecnológica, basada en el limitante y en la oferta tecnológica para solucionarla. Elaborado el diagnóstico, estructuró un Plan Nacional de Investigación (Plania) en el cual indicó y jerarquizó las áreas de investigación, con base en la importancia de los problemas a resolver y en la oferta tecnológica disponible. La investigación propuesta en el Plania respecto a hortalizas comprendió 18 especies y propuso 38 proyectos en las disciplinas de mejoramiento, fisiología, entomología, fitopatología, procesos y suelos. En 1989, el Programa de Hortalizas pasó a ser una Sección Nacional constituida por un Grupo Multidisciplinario. A partir de 1993, las actividades de investigación agropecuaria pasaron a la Corporación Colombiana de Investigación Agropecuaria (Corpoica), que en sus primeros años realizó un esfuerzo tendiente a priorizar las especies, sus problemas y las posibles soluciones tecnológicas (Pinzón, 1997; Rondón y Becerra, 1996).

Teniendo en cuenta que el país adolece de una gran "central de datos" que recopile el historial investigativo agropecuario nacional, la siguiente constituye una aproximación a los principales logros alcanzados en la investigación en cebollas y ajo durante los últimos años:

\section{Cebolla de bulbo}

Las cebollas en general aparecieron como especies prioritarias en la mayoría de estas entidades y programas de investigación. En sus primeros años, el ICA privilegió los estudios de fertilización e incorporó los de fitopatología y entomología, luego acogió la política de evaluación de materiales (semillas) importados en especies hortícolas de propagación sexual, como los de cebolla de bubo. A Colombia llegan semillas provenientes principalmente de Estados Unidos (las de mayor demanda), Europa, Israel y Japón, y últimamente las evaluaciones han estado dirigidas a seleccionar híbridos de tipo Sweet (cebollas menos picantes) y con un tiempo razonable de almacenamiento (López y Ávila, 1996). 
El manejo de enfermedades se ha abordado teniendo en cuenta los factores principales que inciden en ellas, como el manejo del agua para riego y la fertilización adecuada. En un proyecto financiado por el Ministerio de Agricultura y Desarrollo Rural y Asohofrucol, actualmente se trabaja en los estudios preliminares para implementar sistemas de fertirriego en la zona de producción de Sogamoso (Boyacá), con miras a fomentar el ahorro en el consumo de agua y a fertilizar de acuerdo con los requerimientos de la planta y el suelo. En el transcurso de los años, se han efectuado diagnósticos y trabajos tendientes a la identificación y manejo de los patógenos que afectan al follaje y especialmente al bulbo; sin embargo, al tema no se le ha otorgado la importancia que debería tener y los problemas prevalecen.

Nuestras condiciones ambientales son variables y por esa razón hay dificultad para curar los bulbos en campo después de su cosecha, por tanto, a los diversos ensayos de secado natural que utilizan cubiertas de protección se agregó un estudio incluido en un proyecto sobre "Producción y tecnologías de curado y almacenamiento de cebolla de bulbo", financiado por Sena y Asohofrucol en 2005, el cual utiliza prototipos de secamiento con aire forzado, en los que el aire es calentado mediante quemadores de combustible (coque, ACPM) y se hace pasar un flujo de aire a través de las cebollas, retirando de esta manera la humedad de los dos o tres catáfilos exteriores de los bulbos; la temperatura del aire para el secado puede variar entre $35^{\circ} \mathrm{C}$ y $45^{\circ} \mathrm{C}$, de esta condición depende el tiempo de secado, que es aproximadamente 24 h (Pinzón et al., 2003; Suárez y Cadena, 2005).

\section{Cebolla de rama}

Con la finalidad de preservar los materiales existentes y conocer su variabilidad, el ICA, en 1980, inició las colecciones de cebolla de rama, en 1984 ya se tenía un Banco de 34 clones y en la actualidad se cuenta con 60. El análisis de esa colección arrojó diferencias significativas para las variables cuantitativas y cualitativas, especialmente para rendimiento, número y peso de tallos; el análisis multivariado definió seis grupos para doce variables analizadas, las cuales explican el $64 \%$ de la variabilidad total encontrada y se halló que la interacción genotipo-ambiente fue significativa para caracteres asociados con rendimiento (Jaramillo et al., 1986; Rozo y Tinjacá, 1995).

A partir de 1985, el ICA llevó los mejores materiales de la Colección para Aquitania, con el propósito de evaluarlos y seleccionar los de mejor adaptación, comportamiento agronómico y sanitario y mejor calidad (pungencia, color, grosor). En 1995, se presentó una carencia de recursos económicos en Corpoica y hubo que suspender esas evaluaciones, por esta razón un agricultor multiplicó por su cuenta el clon que presentaba las mejores perspectivas, le puso nombre y lo comercializó con buena aceptación en su comienzo, pero, desafortunadamente, no pudo sostener la pureza del material y éste se perdió. Posteriormente y con intermitencias se prosiguió la tarea de las evaluaciones en Aquitania y en la actualidad hay en marcha un proyecto financiado por el Ministerio de Agricultura y Desarrollo Rural, destinado a obtener variedades para esa región (Herrera et al., 2006a).

En 2005, Corpoica comenzó a trabajar en un proyecto, financiado en parte por Corpoboyacá, destinado a desarrollar procesos de innovación y tecnologías de producción más limpias, a través de un programa integral para prevenir y mitigar impactos ambientales negativos generados por el cultivo de cebolla en Aquitania. Los aspectos más relevantes de este programa fueron (Herrera et al., 2006):

- La obtención del protocolo de producción de plantas in vitro de cebolla de rama. Se cumplieron las etapas de selección de plantas donantes, desinfección de esas plantas, el proceso de introducción in vitro de ápices y el proceso de multiplicación in vitro de plántulas El proyecto se encuentra suspendido. 
- Investigar y producir biabono a través de un proceso de compostaje, utilizando inóculos microbianos y a partir de residuos de elodea, cebolla y gallinaza; este proceso se ha continuado en manos de una cooperativa privada, Asoparcela.

- Con el concurso de la Corporación PBA, el fortalecimiento de la capacidad asociativa de los productores con la creación y consolidación de Asoparcela, entidad que agrupa en la actualidad cerca de 50 socios productores de cebolla.

- Mediante reconocimientos en campo e identificación en laboratorio de las enfermedades más limitantes, se obtuvo información valiosa sobre la presencia de Ditylenchus dipsaci, Pseudomonas sp., Peronospora destructor, Stemphylium alli y Cladosporium allí.

Corpoica en 2008, con financiación del Ministerio de Agricultura y Asohofrucol, desarrolló un proyecto de carácter sanitario para el estudio sobre la interacción del nemátodo Ditylenchus dipsaci (Kuhn) y la bacteria Burkholderia cepacia (Hio, 2009) y su relación con la pudrición radical en cebolla de rama. Entre sus resultados más importantes se destacan los siguientes: descripción de los cambios morfológicos de plantas de cebolla, ocasionados por los microorganismos patógenos involucrados en el proceso de la enfermedad; descripción de síntomas de pudrición radical de plantas de cebolla en campo; aislamiento de bacterias a partir de material vegetal y suelo; extracción de nemátodos; sinergismo entre los microorganismos relacionados con la pudrición radical e incidencia de la enfermedad (pudrición radical) en condiciones de campo (Hio, 2009; Corporación Colombiana de Investigación Agropecuaria, 1997).

\section{Ajo}

En 1982, el ICA inició y completó un banco de germoplasma de ajo consistente en 20 clones provenientes de diferentes regiones del país. Entre 1990 y 1991, a esta colección se le hicieron estudios de caracterización para conocer su variabilidad genética disponible; el análisis de las variables canónicas y del dendograma indicó una diversidad genética que permitió su clasificación en cuatro grupos genéticamente uniformes y se definieron algunos genotipos aptos para incluirlos en un programa de selección de clones por su precocidad, uniformidad del bulbo y porte de la planta (Ligarreto, 1991).

En 1994, Corpoica estructuró un proyecto destinado a obtener la primera variedad nacional mejorada de ajo. Ésta fue obtenida en un proceso investigativo de cinco años a través de la caracterización, evaluación y selección de diez clones promisorios, cinco de ellos de origen argentino, los cuales fueron enviados al ICA en 1992 por la Red de Cooperación Técnica en producción de cultivos que auspicia la FAO; los otros cinco eran los mejores materiales pertenecientes al Banco de Germoplasma del ICA. Como producto de este trabajo, surgió la variedad denominada Rubí-1 y en 2004 a Corpoica le fue concedido el Certificado de Obtentor (Pinzón, 1999; Ballesteros y Gómez, 2004). Después de estar un tiempo en el mercado, esta variedad fue retirada provisionalmente mientras se accedía a un protocolo de multiplicación in vitro con el propósito de obtener semillas limpias.

Colciencias, en 2004, financió a Corpoica un proyecto para desarrollar procesos de innovación tecnológica para la producción de ajo Rubí-1 basado en el preescalamiento de semillas limpias de alta calidad, el secamiento y almacenamiento y mediante la técnica de cultivo in vitro de meristemos (Parra, 2006). Este proyecto actualmente se encuentra en ejecución.

En la actualidad, el Centro de Investigaciones y Asesorías Agroindustriales (CIAA) de la Universidad Jorge Tadeo Lozano está desarrollando dos proyectos financiados por el Ministerio de Agricultura y Asohofrucol destinados a la evaluación participativa de tecnologías de manejo integrado de plagas para los principales limitantes fitopa- 
togénicos Sclerotium cepivorum y nemátodos y el mejoramiento de la competitividad del ajo en Colombia mediante el ajuste participativo de tecnologías disponibles para la obtención y comercialización de semillas garantizadas.

\section{PERSPECTIVAS}

Las perspectivas de este grupo de especies hortícolas nacen de su importancia: de acuerdo con el Plan Hortícola Nacional (PHN) la tendencia histórica muestra que la cebolla de bulbo domina la producción hortícola, seguida de la cebolla de rama, y estas mismas especies dominan el área de producción, después de la arveja. De hecho, entre los 15 productos de mayor preferencia para los colombianos en su canasta alimenticia diaria se encuentran el tomate, la cebolla cabezona y la zanahoria. El tomate es la hortaliza más consumida con $38 \%$ de preferencia y una cantidad diaria de aproximadamente $45 \mathrm{~g}$ y la cebolla cabezona es la siguiente con $30 \%$ de preferencia y una cantidad diaria de aproximadamente $31,8 \mathrm{~g}$. Por otro lado, las importaciones colombianas de cebollas y ajo, entre frescas y secas, alcanzaron en 2006 un valor de 18 millones de dólares, cifra que constituye un $52 \%$ del valor total de las importaciones nacionales de hortalizas (Corporación Colombiana Internacional, 2007; Jaramillo, 2006).

Como se expuso anteriormente, es de anotar que ha habido respuesta de algunas entidades de investigación a la problemática puntual del sector de los Alliums comestibles, si bien no en la proporción que se requiere. Sin entrar en zonas críticas de manejo político, como las de comercialización y precios, no es claro el panorama que se visualiza: por un lado, las áreas de siembra disminuyen y las zonas infectadas por enfermedades crecen amenazando zonas nuevas y, por otro lado, los recursos de financiación para investigación compiten con otros sectores agrícolas.
Recordemos, además, que los Alliums comestibles en Colombia constituyen un sector de alto impacto socio-económico que demanda de casi tres millones de jornales anuales, aporta más de $500.000 \mathrm{t}$ de productos frescos para el consumo y favorece otros sectores sensibles de la economía como el transporte y la producción de insumos para el cultivo (Ministerio de Agricultura y Desarrollo Rural, 2005).

Es claro que dos grandes problemas se destacan actualmente y merecen la máxima atención, desde el punto de vista de la investigación, ellos son las enfermedades y la calidad sanitaria de las semillas de propagación asexual. Como se aprecia en la breve reseña de proyectos desarrollados y en curso, el aspecto fitopatológico no ha sido el más importante y requiere la máxima atención $y$, por otro lado, tanto a los proyectos sobre evaluación y selección de materiales destinados a la obtención de nuevas variedades como a los estudios para obtener "semillas limpias", acudiendo a la herramienta de la biotecnología, se les debe garantizar su continuidad.

Sin embargo, es necesario resaltar algunos aspectos que pueden ayudar en la búsqueda de soluciones a la problemática global de estas especies:

- La falta de capacidad asociativa de los productores dificulta tener interlocutores para la elaboración y presentación de proyectos que los beneficien y apoyen cuando se están desarrollando.

- El sector privado difícilmente aporta recursos para, por lo menos, apoyar económicamente en un porcentaje a los proyectos que demanda la comunidad de productores.

- La investigación, en nuestro medio, necesita priorizar regularmente sus objetivos y alcances y necesita planes sostenidos a mediano y largo plazo. 
- Si bien las individualidades están presentes en todas las actividades, es necesario privilegiar y fortalecer el sentido de equipo de trabajo. Los grupos de investigación-extensión de carácter multidisciplinario son importantes en este proceso.

La perspectiva en Colombia, desde el punto de vista relacionado con la agroindustria de los Alliums comestibles es todavía muy reducida, debido a que, en general, a pesar de la estacionalidad de la oferta, se encuentran productos frescos todo el año. Sin embargo, los nuevos requerimientos en los mercados, ocasionados por los cambios en la sociedad relacionados con la participación de la mujer en el mercado laboral, menos tiempo en el hogar, personas independientes y la practicidad de los alimentos preparados, están empezando a generar cambios, que seguramente se acelerarán a corto plazo. Las estadísticas comerciales mundiales muestran claramente el gran incremento que se ha experimentado en el comercio mundial de procesados, esta situación es una tendencia mundialy, por tanto, Colombia deberá producir y comercializar de acuerdo con los requerimientos de la demanda. En el mercado local, ya se están ofertando diversas presentaciones de Alliums (vinagreta, deshidratados, cremas, concentrados). Sin embargo, es difícil conseguir información sobre el estado actual de esa agroindustria, porque todavía su producción es muy pequeña (Báez y Díaz, 2005; Corporación Colombiana Internacional, 1994; Pinzón et al., 2006).

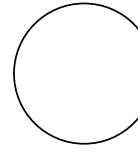

Acosta, A.; J. Gaviola y C. Galvamarini. 1993. Cebolla. Manual de producción de semillas hortícolas. EEA La Consulta. INTA, Argentina.

Agronet. 2009. Producción nacional por producto. En: Análisis y estadísticas, 1997. http://www.agronet. gov.co; consulta: marzo de 2009.

Alonso, A. y M.S. Pinzón. 2002. Situación de la comercialización del ajo en la Central Mayorista de Abastos en Bogotá y su inserción en la cadena hortícola. Trabajo de grado. Universidad de Cundinamarca, Facultad de Ciencias Agropecuarias, Ubaté, Colombia.

Angarita, A. 1998. Distribución, incidencia y severidad de las principales enfermedades de cebolla de rama en la cuenca del lago de Tota. Trabajo de maestría en Ciencias Agrarias. Facultad de Agronomía, Universidad Nacional de Colombia, Bogotá.

Ávila de M., C. 1996. Principales enfermedades del ajo. pp. 73-86. En: López, A. (ed). El cultivo del ajo y las cebollas en Colombia. Produmedios, Bogotá.

Báez, A. y E. Diaz. 2005. Evaluación de dos sistemas de almacenamiento de cebolla de bulbo (Allium cepa) curada utilizando condiciones de refrigeración y aire ligeramente calentado. Trabajo de grado. Facultad de Ingeniería Agrícola, Universidad Nacional de Colombia, Bogotá. 79 p.

\section{REFERENCIAS BIBLIOGRÁFICAS}

Ballesteros, C.A. y L.E. Gómez. 2004. Estudio de la adaptabilidad del ajo Rubí-1 en la Región del Sumapaz. Trabajo de grado. Facultad de Ciencias Agropecuarias, Universidad de Cundinamarca, Fusagasugá, Colombia.

Brewster, J.L. 1990. Physiology of crop growth and bulbing. pp. 53-88. En: Rabinowicht, H.D. y J.L. Brewster (eds.). Onions and allied crops. Vol.1. CRC Press, Boca Raton, FL.

Brewster, J. 2001. Las cebollas y otros alliums. Editorial Acribia, Zaragoza, España.

Calderón, P.N. 1999. Sondeo del mercado del ajo en Colombia. Corpoica, Mosquera, Colombia.

Caicedo, L. 1972. Curso de horticultura. Facultad de Ciencias Agropecuarias, Universidad Nacional de Colombia, Palmira.

Casseres, E. 1980. Producción de hortalizas. Instituto Interamericano de Ciencias Agrícolas, San José de Costa Rica.

Corporación Colombiana Internacional. 1994. Análisis Internacional del sector hortifrutícola para Colombia. Serie CCI Informes técnicos, No. 1. Bogotá.

Corporación Colombiana Internacional. 2007. Plán Hortícola Nacional. CCI, Bogotá. 
Corporación Colombiana de Investigación Agropecuaria. 1997. Control biológico de fitopatógenos. Seminario internacional. Produmedios, Bogotá.

Departamento Administrativo Nacional de Estadística. 2001. Primer censo del cultivo de cebolla larga en la Región de la laguna de Tota. DANE, Bogotá.

Galmarini, C. 1990. Caracterización de cultivares argentinos de cebolla (Allium cepa) de acuerdo a sus requerimientos de vernalización. Tesis de maestría. Instituto Agronómico Mediterráneo de Zaragoza, España.

Gaviola, J. y N. Oliva. 1985. Efectos de la densidad de plantación de bulbos de cebolla (Allium cepa) sobre el rendimiento y la calidad de la semilla. pp. 1-39. En: Resúmenes XI Seminario Panamericano de Semillas. Cali, Colombia.

Hanelt, P. 1990. Taxonomy, evolution and history. pp. 1-26. En: Rabinowicht, H.D. y J.L. Brewster (eds.). Onions and allied crops. Vol.1. CRC Press, Boca Raton, FL.

Hio, J.C. 2009. Estudio sobre la interacción del nematodo Ditylenchus dipsaci (Kuhn) y la bacteria Burkholderia cepacia (Palleroni and Holmes 1981) y su relación con la pudrición radical en cebolla de rama Allium fistulosum L., en el municipio de Aquitania (Boyacá). Tesis de Maestría en Biología Aplicada. Facultad de Ciencias, Universidad Militar Nueva Granada, Bogotá.

Herrera, C.; G. Sánchez y V. Peña. 2006a. Avances de resultados de investigación en cebolla de rama en Aquitania, Boyacá. Produmedios, Bogotá.

Herrera, C.; M. Laitón y G. Sánchez. 2006b. Cebolla de bulbo. Guía para la implementación de buenas prácticas agrícolas. Produmedios, Bogotá.

Instituto Colombiano Agropecuario. 1983. Hortalizas. Manual de asistencia técnica. División de Comunicación del ICA, Bogotá.

Jaramillo, J.; Y. Palacios y O. Martínez. 1986. Descripción cuantitativa de la colección colombiana de cebolla de rama. ICA, Mosquera, Colombia.

Jaramillo, J.E. 2006. Situación de la producción de las hortalizas en Colombia y sus perspectivas. pp. 137 149. En: Memorias Primer Congreso Colombiano de Horticultura. Sociedad Colombiana de Ciencias Hortícolas, Bogotá.

Jones, H. y Mann, L. 1963. Onions and their allies. Leonard Hill, London. pp. 36-38.

Ligarreto, G.A. 1991. Caracterización morfológica y electroforética de cultivares de ajo. Trabajo de grado. Facultad de Agronomía, Universidad Nacional de Colombia, Bogotá.
López, A. y C. Ávila. 1996. Manejo fitosanitario del ajo y las cebollas. Produmedios, Bogotá.

López, E. y J. Heredia. 1997. Evaluación de diferentes densidades de siembra en la propagación vegetativa de la cebolla de rama (Allium fistulosum) en condiciones de la Sabana de Bogotá. Trabajo de grado. Facultad de Agronomía, Universidad Nacional de Colombia, Bogotá.

Ministerio de Agricultura y Desarrollo Rural, IICA. 2005. La competitividad de las cadenas agroproductivas en Colombia: análisis de su estructura y dinámica. (1991-2004). Bogotá.

Ministerio de Agricultura y Desarrollo Rural. 2006. Acuerdo de competitividad de la Cadena de Hortalizas. Bogotá.

Parra, M. 2006. Desarrollo de tecnologías para la producción de semilla prebásica indexada de ajo (Allium sativum, L.) var. Rubí-1 y criollo en el Laboratorio de Micropropagación de Plantas de Corpoica C.I. Tibaitatá del Municipio de Mosquera-Cundinamarca. Trabajo de grado. Facultad de Ciencias Agrarias y del Ambiente, Universidad Francisco de Paula Santander, Colombia.

Pinzón, H. 1996. Botánica, morfología y fisiología. pp. 9-16. En: López, A. (ed.). El cultivo del ajo y las cebollas en Colombia. Produmedios, Bogotá.

Pinzón, H. 1997. Consideraciones para la investigación hortícola en Colombia. Corpoica, Mosquera, Colombia.

Pinzón, H. 1999. Rubí-1 primera variedad colombiana de ajo. Produmedios, Bogotá.

Pinzón, H. 2002. Producción de Alliaceas. pp 11-13. En: Memorias Taller de Hortalizas, Productividad y Mercadeo. Produmedios, Bogotá

Pinzón, H. 2003. Producción de semillas de algunas alliáceas. pp. 33-36. En: Memorias II Taller de Hortalizas, Productividad y Mercadeo. Produmedios, Bogotá.

Pinzón, H. 2004. La cebolla de rama (Allium fistulosum) y su cultivo. Produmedios, Bogotá.

Pinzón, H. 2008. El cultivo del ajo. Manejo empresarial del campo. Produmedios, Bogotá.

Pinzón, H.; J. Ospina y A. Baez. 2006. Curado y almacenamiento de cebolla de bulbo. Editorial Litolaser, Bogotá.

Pinzón, H.; J. Torres; P. Prada y L. Barrera. 2003. Informe final proyecto: Validación participativa y transferencia de tecnología para la producción sostenible de cebolla de bulbo, cebolla de rama y ajo en Cundinamarca y Boyacá. Corpoica, Bogotá. 
Raymond, P. 1990. El lago de Tota ahogado en cebolla. Serie investigación y desarrollo No. 1. Facultad de Ciencias Económicas y Administrativas, Pontificia Universidad Javeriana. Editorial Presencia, Bogotá.

Rico, L. y M. Ávila 1989. Estudios preliminares sobre el efecto de un virus en ajo. p. 18. En: Memorias XXIX Congreso de Ascolfi, Cali.

Rondón, S. y N. Becerra. 1996. Efecto de las coberturas plásticas en dos sistemas de siembra sobre el crecimiento y desarrollo de la cebolla de bulbo (Allium cepa) en la Sabana de Bogotá. Trabajo de grado. Facultad de Agronomía, Universidad Nacional de Colombia, Bogotá.

Rozo, I. y G. Tinjacá. 1995. Caracterización morfológica de cultivares de la colección colombiana de cebolla de rama Trabajo de grado. Facultad de Agronomía, Universidad Nacional de Colombia, Bogotá.
Suarez, L. y D. Cadena. 2005. Estudio del secado en cebolla de bulbo (Allium cepa). Trabajo de grado. Departamento de Ingeniería Agrícola, Universidad Nacional de Colombia, Bogotá.

Tovar, D.R.; A.M. Yara y L.P. Zuleta. 1997. Estudio preliminar para control biológico de Sclerotium cepivorum en cebolla de bulbo y Ditylenchus dipsaci en cebolla de rama. Trabajo de grado. Facultad de Ciencias de la Salud, Universidad Colegio Mayor de Cundinamarca, Bogotá.

Vergel, L.; J. Jaramillo y P. Conde. 2003. Producción de cebolla de bulbo ocañera. Manual técnico. Litografía La Bastilla, Bucaramanga, Colombia.

Vergel, L.; C. Terán y C. Gómez. 2004. Manejo de riego en cebolla ocañera. Manual técnico. Litografía La Bastilla, Bucaramanga, Colombia. 